\title{
Immediate Implant Placement with Simultaneous Regenerative Procedure in Fresh Extraction Socket
}

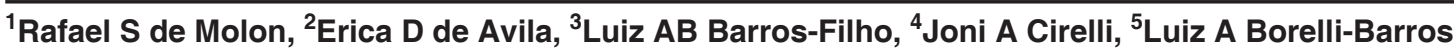

\begin{abstract}
Aim: The aim of this case report was to reconstruct the alveolar buccal bone plate lost in consequence of a root fracture in the maxillary central incisor area after immediate implant placement (IIP). A 48-year-old patient was referred to our office with the chief complaint of spontaneous bleeding in his left central incisor. After careful examination, the following comprehensive treatment approach was carried out: (1) Atraumatic tooth extraction, (2) IIP, (3) provisional prosthesis installation, (4) alveolar buccal bone plate reconstruction with autologous bone collected from the maxillary tuberosity, (5) gingival augmentation procedure with connective tissue graft removed from the palate, and finally (6) adjustment of the provisional restoration. After 1-year postoperative, an adequate esthetic outcome was achieved with lower cost, reduced morbidity to the patient, and lower treatment time. This approach was able to improve gingival architecture and bone volume with adequate thickness and width, enhancing patient esthetics and satisfaction. In conclusion, when proper diagnosis, precise surgical techniques, and appropriate multidisciplinary approach are employed, IIP followed by immediate dentoalveolar restoration might be considered a safe procedure to restore the peri-implant bone and gingival recession favoring the achievement of appropriate esthetic outcomes.

Clinical significance: The treatment planning employed was able to improve gingival architecture and bone volume with sufficient width and thickness enhancing patient esthetics and satisfaction in one single-stage procedure.
\end{abstract}

Keywords: Alveolar bone loss, Connective tissue, Esthetics, Immediate dental implant.

\footnotetext{
${ }^{1}$ Department of Rheumatology, Rheumatology Research and Advanced Therapeutics, Radboud University Nijmegen Medical Centre, 6500 HB Nijmegen, Netherlands; Department of Diagnosis and Surgery, School of Dentistry at Araraquara, São Paulo State University - UNESP, Araraquara, São Paulo, Brazil

${ }^{2}$ Department of Dental Materials and Prosthodontics, School of Dentistry at Araraquara, São Paulo State University - UNESP Araraquara, São Paulo, Brazil

${ }^{3,4}$ Department of Diagnosis and Surgery, School of Dentistry at Araraquara, São Paulo State University - UNESP, Araraquara São Paulo, Brazil

${ }^{5}$ Department of Social Dentistry, School of Dentistry at Araraquara, São Paulo State University - UNESP, Araraquara São Paulo, Brazil

Corresponding Author: Rafael S de Molon, Department of Rheumatology, Rheumatology Research and Advanced Therapeutics, Radboud University Nijmegen Medical Centre 6500 HB Nijmegen, Netherlands; Department of Diagnosis and Surgery, School of Dentistry at Araraquara, São Paulo State University - UNESP, Araraquara, São Paulo, Brazil Phone: +310645465780, e-mail: rafael.scafdemolon@radboudumc.nl
}

How to cite this article: de Molon RS, de Avila ED, BarrosFilho LAB, Cirelli JA, Borelli-Barros LA. Immediate Implant Placement with Simultaneous Regenerative Procedure in Fresh Extraction Socket. World J Dent 2017;8(3):231-238.

\section{Source of support: Nil}

Conflict of interest: None

\section{INTRODUCTION}

Implant placement immediately after tooth extraction in the esthetic area has been introduced into clinical practice since $1978^{1}$ as an alternative approach for a faster oral rehabilitation. Immediate implant placement (IIP) has some advantages compared with conventional treatment, in which a period between 3 and 6 months should be awaited before implant installation, such as reduced number of surgical procedures, shorter length of treatment, immediate function, potentially lower cost, and fewer restorations. ${ }^{2-4}$ Although the survival rate observed for IIP is higher than $98 \%$ as evidenced in the previous study, ${ }^{5}$ particularly attention should be paid to the esthetic outcomes. In the maxillary esthetic region, gingival recession and collapse of the alveolar process is a common complication after IIP due to multiple factors, i.e., thin gingival biotype, loss of buccal bone wall, surgical flap reflection, and delayed crown restoration. ${ }^{6}$ Such characteristics may contribute to higher risk of midfacial recession and absence of interproximal papillae especially in patients with a high smile line. Because gingival tissue follows the changes of the underlying bone, ${ }^{7}$ alveolar buccal bone remodeling in a coronal direction occurs after tooth extraction resulting in the shift of the gingival tissue position. ${ }^{8,9}$

To avoid esthetic complications and to increase the success rate of IIP in the esthetic region, several procedures and precautions should be addressed to prevent postextraction bone loss. Alveolar ridge preservation using autogenous bone and soft tissue grafts or biomaterials, atraumatic tooth extraction, flapless surgery, and appropriate implant position has been proposed to prevent the dimensional changes in the alveolar ridge. ${ }^{4}$ Thus, these techniques are recommended for optimizing functional and esthetic outcomes. For this, some prerequisites for the successful employment of IIP include the absence of active infection or acute inflammation, appropriate bone quantity in the alveolar socket apex to allow adequate primary stability of the implant, undamaged buccal bone after teeth extraction, 
absence of extensive gingival recession, and no intimate relationship with the nasal cavity and maxillary sinus. ${ }^{10,11}$

Aiming to preventing esthetic complications, to increase clinical effectiveness, to increase patient acceptance, to reduce the total amount of procedures, to reduce bone morphological changes over time, and to allow faster restoration of function, a single appointment approach was utilized, in which immediate dentoalveolar restoration technique was used to restore peri-implant buccal bone defect after IIP, followed by connective graft placement and immediate crown restoration.

\section{CASE REPORT}

A 48-year-old Caucasian man was admitted to the Department of Diagnosis and Surgery at the School of Dentistry with the chief complaint of spontaneous bleeding, swelling, and suppuration on his left central incisor. He denied use of alcohol and had no relevant systemic alterations. Clinical inspection showed class II tooth mobility in his left central incisor, with 8 and $4 \mathrm{~mm}$ probing depth in the mesial and distal side of the left incisor respectively, with advanced resorption of the buccal bone plate near to the root apex (Figs 1A to C). Radiographic examination showed a definitive fixed prosthesis, endodontic treatment, and vertical alveolar bone breakdown. The height of the alveolar bone above the tooth apex was $10 \mathrm{~mm}$ (Fig. 1D). After careful clinical and radiographic examinations, a single-staged combined approach for the treatment of a hopeless tooth was employed using IIP, immediate dentoalveolar restoration followed by connective graft placement and provisional prosthesis installation. The patient accepted the above treatment protocol and signed an informed permission before the commencement of the surgical procedures.

The first step in the rehabilitation procedure was to perform atraumatic extraction of the hopeless tooth using a flapless technique with the aid of a periotome to maintain intact the reminiscent alveolar buccal bone plate and the gingival tissues, especially the interproximal papillae (Figs 1E and F, 2A and B), under local anesthesia (Mepivacaine 1:100.000 - Mepiadre ${ }^{\circledR}$, DFL, RJ, Brazil). Meticulous curettage of the alveolus was accomplished to eliminate
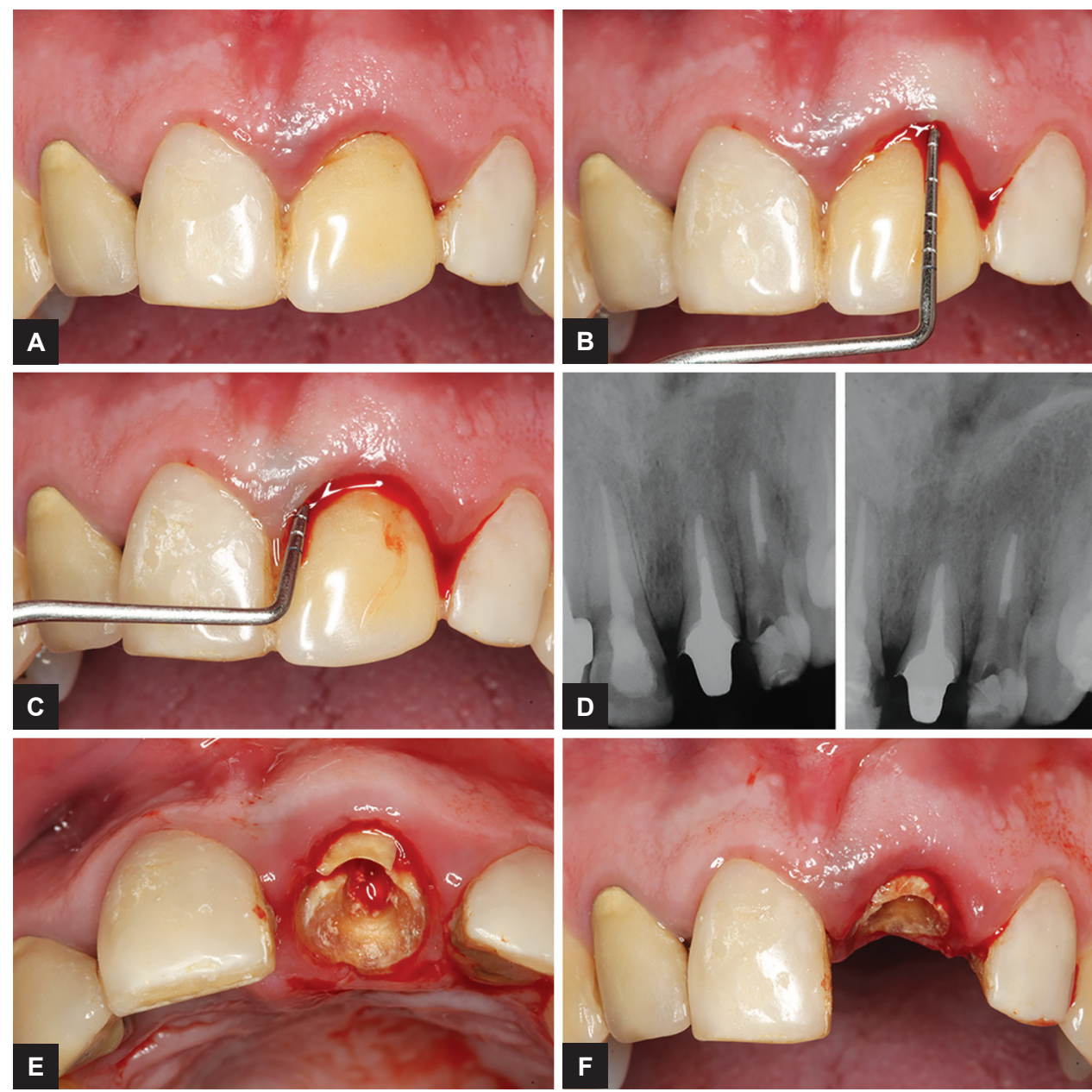

Figs 1A to F: $(A-C)$ Clinical examination of the left central incisor showing bleeding on probing, swelling, and probing depth of $8 \mathrm{~mm}$ in the mesial aspect of the tooth; (D) periapical radiograph evidencing localized vertical resorption, resin-fused-to-metal crown and endodontic treatment; $(E$ and $F$ ) atraumatic extraction of a hopeless tooth with a flapless technique with the aid of a periotome to preserve the reminiscent buccal bone 

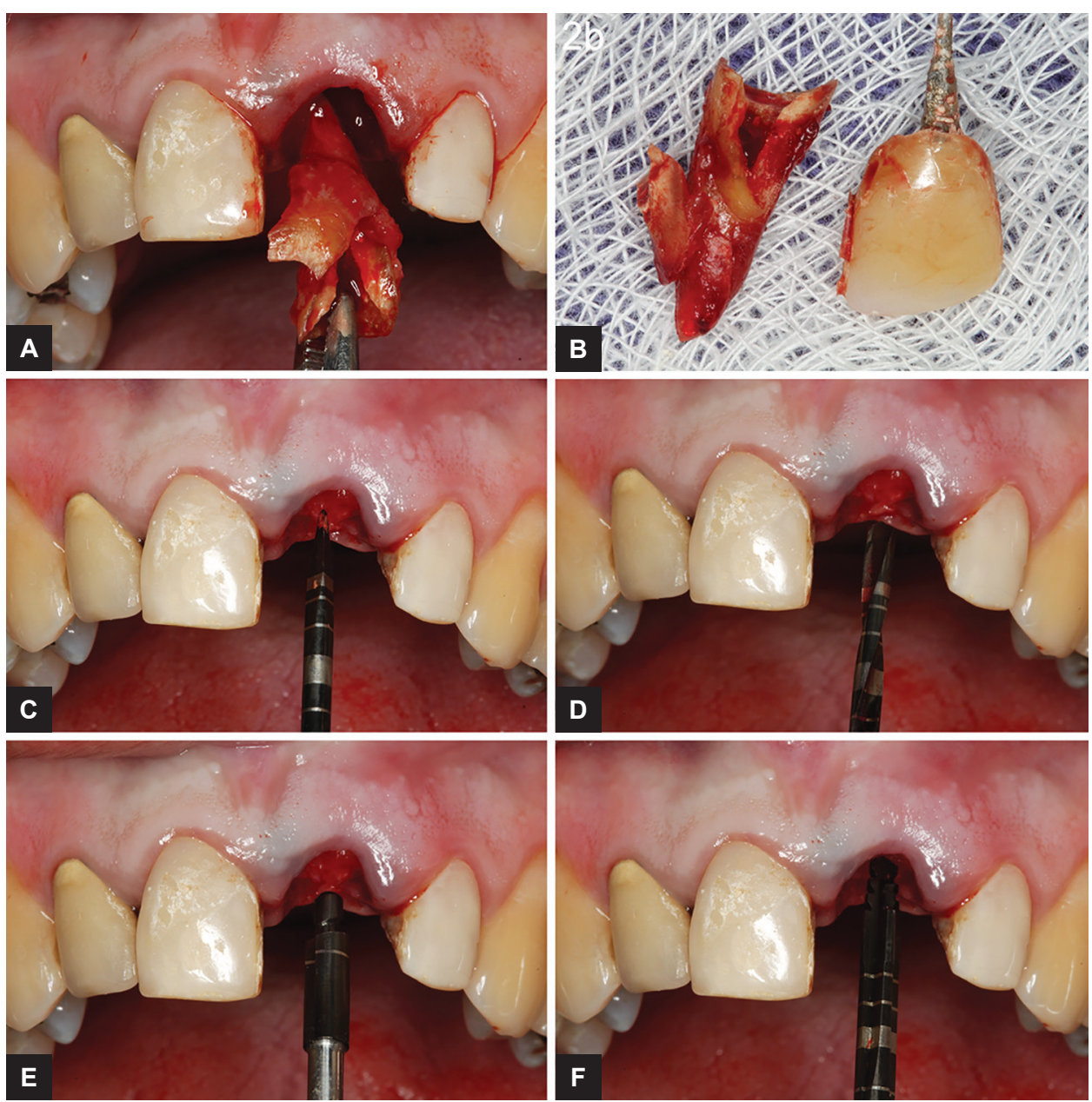

Figs 2A to F: (A and B) Atraumatic extraction of a hopeless tooth with a flapless technique with the aid of a periotome to preserve the reminiscent buccal bone; and $(\mathrm{C}-\mathrm{F})$ Implant bed preparation following all the necessary steps of perforation starting with the spear drill, $2.0 \mathrm{~mm}$ cylindrical drill, pilot drill, and $2.8 \mathrm{~mm}$ conical drill

any inflammatory soft tissue, and the alveolar socket was probed to access bone loss. Due to the inflammatory process in consequence of a fractured root, resorption of the buccal bone plate was present. Measurements of the bone defect were assessed to establish the defect anatomy. Thereafter, implant bed preparation was carried out following all the required steps of drilling starting with the spear drill (Fig. 2C), $2.0 \mathrm{~mm}$ cylindrical drill (Fig. 2D), pilot drill (Fig. 2E), $2.8 \mathrm{~mm}$ conical drill (Fig. 2F), and $3.5 \mathrm{~mm}$ conical drill (Fig. 3A). Then, a titanium dental implant with $3.5 \varnothing \times 13 \mathrm{~mm}$ length (Cone Morse Drive, Neodent, Curitiba, PR, Brazil) was placed respecting the appropriate distances recognized to improve esthetic outcomes and to accomplish suitable emergence profile following the instruction of a restorative-driven threedimensional restoration (Figs 3B to D). ${ }^{12}$

Because of the implant insertion into the palatal upper bone socket, an appropriate primary implant stability of $45 \mathrm{Ncm}$ was achieved, which allowed the immediate placement of the provisional prosthesis throughout the installation of a platform-switching titanium cylinder, prefabricated by the manufacturer, and connected to the implant neck (Fig. 3E). The titanium abutment was customized to receive a provisional prefabricated resin crown (Fig. 3F) that was immediately installed over the abutment (Figs $4 \mathrm{~A}$ to $\mathrm{D}$ ) creating sufficient space for tissue accommodation and improving the gingival contour. Fine-tuning of the occlusal contacts was accomplished and any incisal contact was prevented by reducing the height of the provisional crown enabling immediate but limited functional implant loading (Figs 4D and E). Subsequently, provisional prosthesis was removed for final polishing and finishing, and to allow the reconstruction of the buccal bone defect. A periapical radiograph was taken before and after the implant placement (Fig. 4F).

To reconstruct the socket defect, autogenous bone graft was harvested from the maxillary tuberosity aiming to increase both vertical and horizontal dimensions of the socket defect. To gather the autologous bone graft, a full thickness flap was raised (beginning at the center of the tuberosity crest until the second molar tooth) and the graft was removed with a straight chisel. An appropriate size chisel with $2 \mathrm{~mm}$ larger width than the bone defect width in the receptor site was selected. The autogenous 

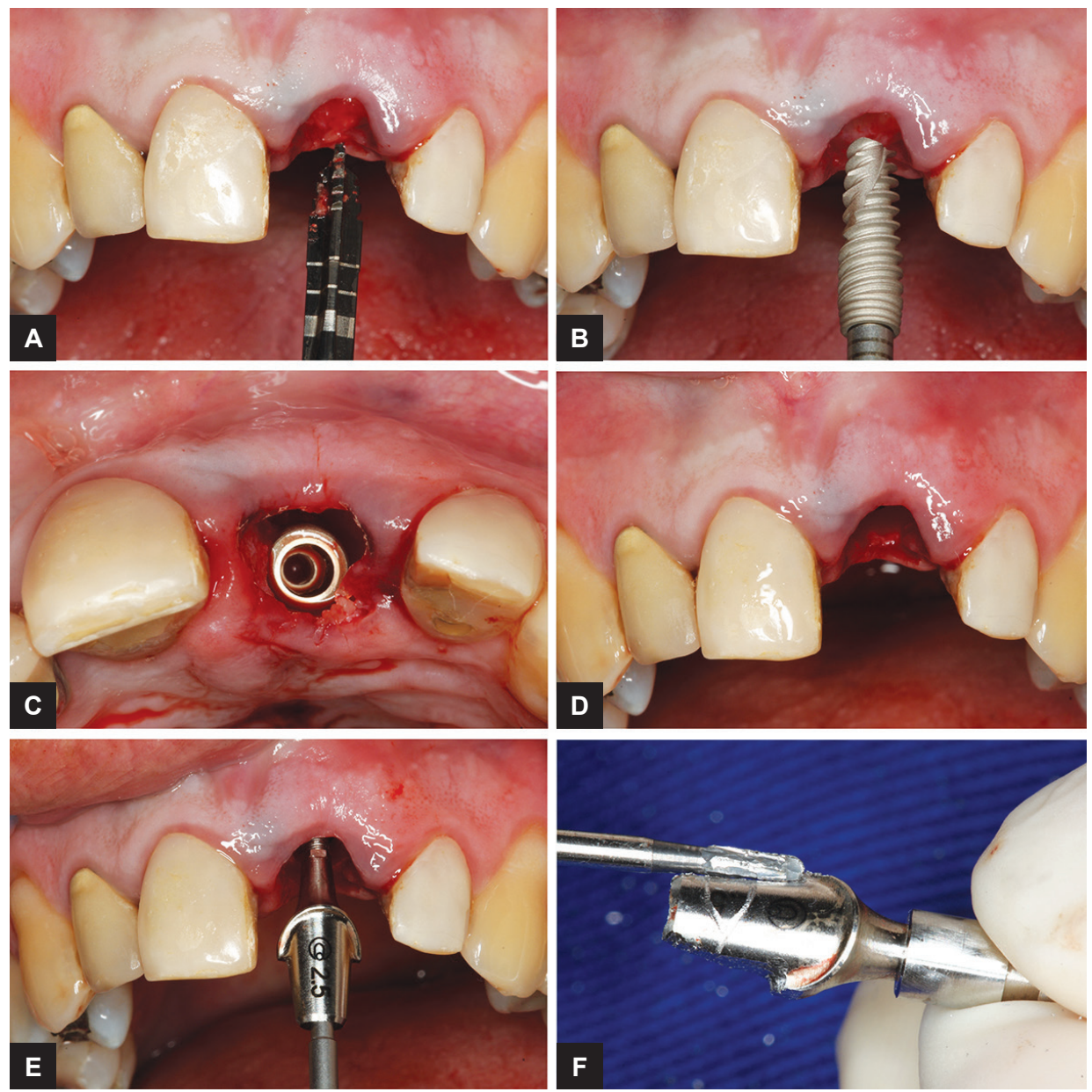

Figs $3 \mathrm{~A}$ to $\mathrm{F}$ : (A and B) $3.5 \mathrm{~mm}$ conical drill for final perforation followed by implant placement; $(C$ and $D)$ Immediate implant placed in an ideal tridimensional position: In the mesiodistal direction, $2 \mathrm{~mm}$ of the adjacent teeth, and the implant shoulder placed $3 \mathrm{~mm}$ apical to the cementoenamel junction of the adjacent central incisor, and the axis of the implant was slightly palatal; ( $E$ and $F$ ) Prosthetic procedures for immediate provisionalization of the crown through the placement of a provisional titanium cylinder connected to the implant neck. The provisional crown was placed temporarily to correct the emergency profile and to create enough space for tissue accommodation

graft was personalized according to the shape and size of the defect, according to previous studies, ${ }^{2,10}$ prepared after careful evaluation of the compromised bone walls of the recipient bed. After harvesting the bone graft, a releasing sulcular incision was performed in the receptor bed, to allow adequate graft positioning at the level of the implant platform (Figs 5A to C). The block bone graft was carefully placed into the defect between the implant and the mucosa. The positioning of the block graft was juxtaposed to the remaining bone walls to ensure adequate block graft stabilization with the cortex turned toward the vestibule. Subsequently, particulate bone was also collected and inserted between the implant and graft to fill the bone-to-implant gap and to assure primary graft stabilization (Fig. 5D).

Autogenous connective graft was also harvested from the palate to increase the gingival thickness in the receptor area due to the thin gingival biotype that would favor gingival recession over time. The connective graft was removed according to the technique described by Hurzeler and Weng ${ }^{13}$ and was inserted above the block bone graft with the aid of a suture thread improving the gingival architecture and the thickness of keratinized gingiva (Figs 5E and F). Simple suture with 5-0 absorbable thread (Ethicon, Johnson \& Johnson SA, São Paulo, Brazil) was performed to avoid connective tissue and block bone graft movement and also to maintain the bone block graft stable. Finally, a fixed provisional prosthesis was installed, and the connective tissue graft was further sutured on the internal face of the flap with simple interrupted sutures (Figs 6A and B).

The sutures were removed after 2 weeks postoperatively and increased width and thickness of the gingival architecture could be seen (Figs 6C to F). The 1-year postoperative results showed the maintenance of the width and thickness of the soft tissue without any alterations of the gingival margin, bone architecture, or probing depths. No bleeding with the probe was detected. This 

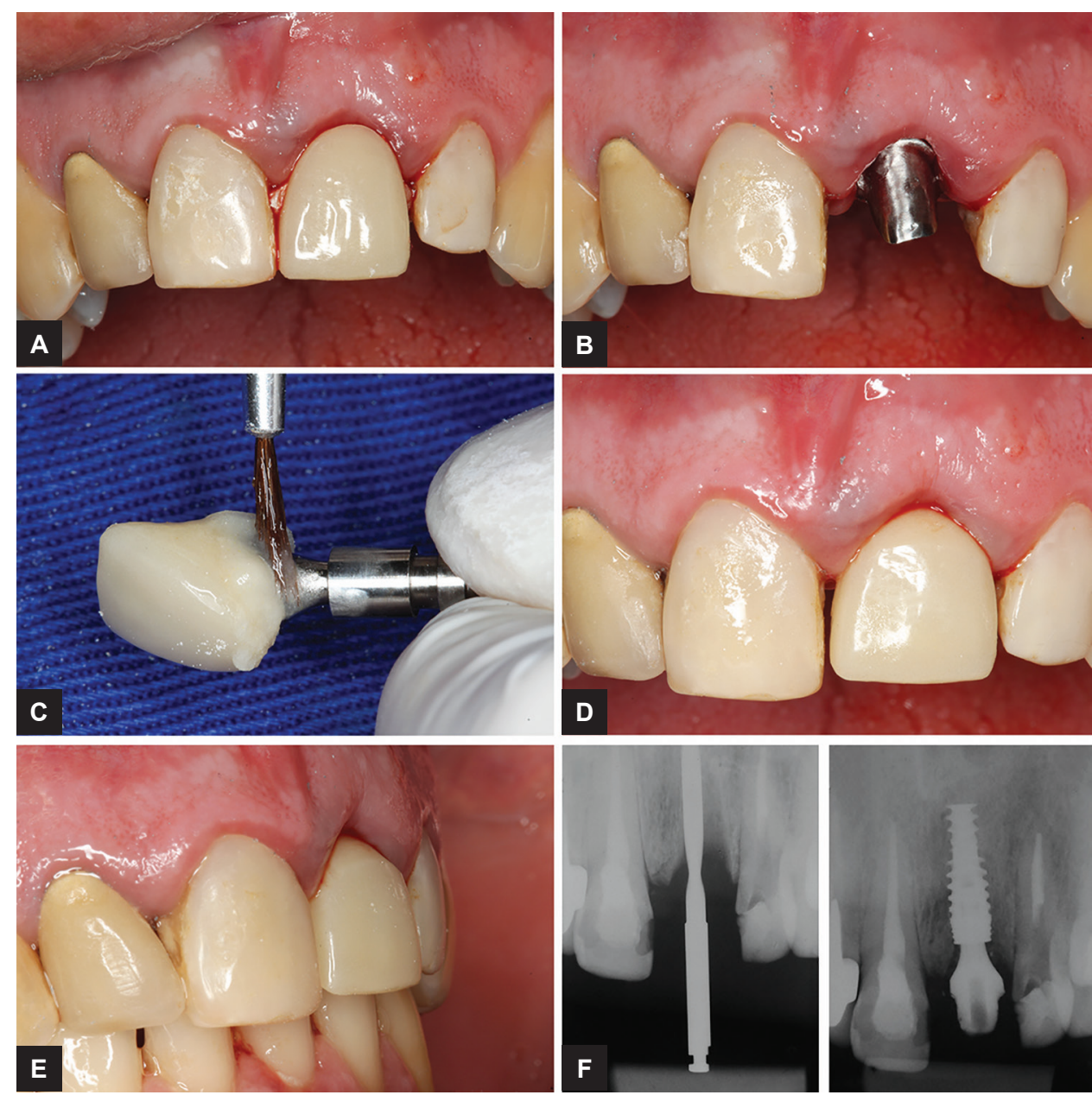

Figs 4A to F: (A-E) Final adjustments of the provisional crown and occlusal shortening of the cervical region of the provisional crown enabling immediate but limited functional loading of the implant; and (F) Final periapical radiographs showing the correct positioning of the implant

treatment protocol was able to restore the functional and esthetic expectations of the patient in relation to the initial pretreatment situation. Unfortunately, due to the financial issues, the patient was not able to afford the new prosthesis, and thus the final definitive prosthesis was not accomplished in this case.

\section{DISCUSSION}

Immediate implant placement has offered foreseeable treatment outcomes and elevated success rate, in particular, cases of single tooth replacement. ${ }^{6,9,14}$ However, morphological alterations of buccal and lingual bone plates after tooth removal might occur if regenerative procedures were not carried out at the moment of implant installation. Surgical complications after IIP are especially related to soft tissue alterations in consequence of a coronal shift of the gingival margin, which tend to follow the underlying bone after buccal bone plate remodeling. Importantly, recent studies ${ }^{15-17}$ showed that alveolar ridge preservation and soft and hard tissue regeneration limit the resorptive process after tooth extraction.
Here, we showed a successful approach to restore the alveolar buccal bone plate after IIP in fresh extraction socket. The reasons for the clinical success of this case were atraumatic extraction of the hopeless tooth and flapless surgery. These approaches allowed preservation of the existing soft and hard tissue using a periotome, which permitted the increasing space between the tooth root and the socket walls facilitating tooth extraction. ${ }^{18}$ Flapless surgery maintained the soft tissue architecture, reduced postoperative discomfort, and allowed conservative tissue manipulation, leaving the periosteum intact to preserve the blood supply. 2,10

Another aspect to consider the clinical safe application of IIP is the implant design and implant position. Adequate implant length to assure enough engage in the palatal upper bone socket is crucial for implant stability that allowed for immediate prosthetic provisionalization. ${ }^{19}$ Here, $6 \mathrm{~mm}$ of vertical bone-to-implant contact was achieved to provide appropriate primary stability. Narrow diameter implant was also used in this case especially because the previous study ${ }^{20} \mathrm{dem}$ onstrated reduced rate of bone loss of implants placed 

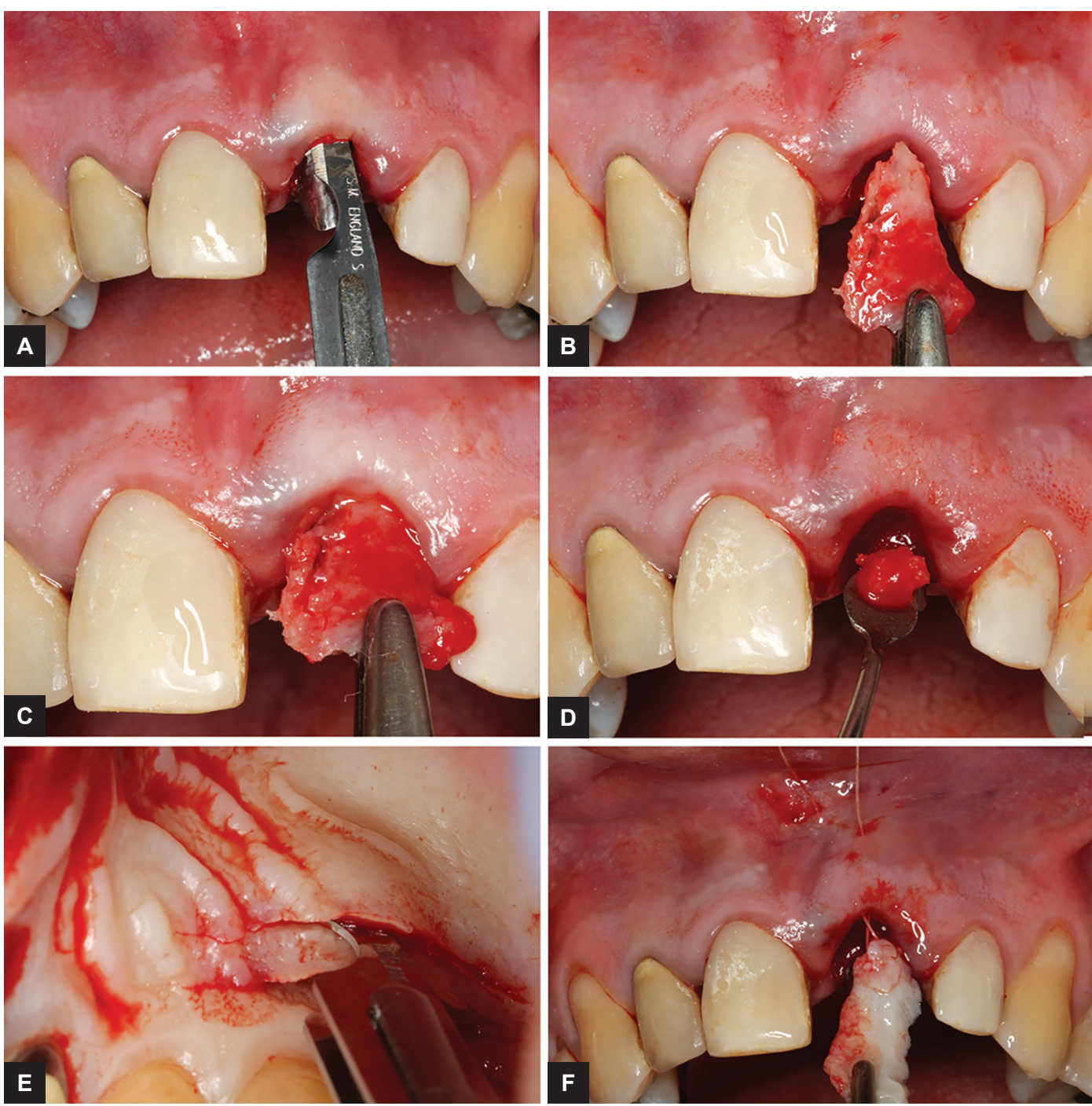

Figs 5 A to F: (A-D) Release of sulcular incision to allow graft installation. Autogenous bone graft harvested from the maxillary tuberosity to create sufficient width and thickness of the buccal bone followed by particulate bone to fill the bone-implant gap; ( $E$ and $F$ ) Connective tissue graft collected from the palate increasing gingival thickness and width

into fresh extraction sockets. In addition, the use of a narrow diameter implant permitted enough space in the alveolus socket to facilitate the graft placement without over-tensioning the gingival tissues favoring the preservation of blood supply. Moreover, a conical shape implant was used in this case to increase the contact between the implant and the bone allowing lateral compaction of the trabecular bone. Implant position is also important for adequate esthetic outcomes. The rule of restorative-driven three-dimensional restoration previously described by Buser et $\mathrm{al}^{12}$ minimizes resorption of the buccal bone plate, in which the implant is positioned in a palatal position conserving satisfactory gap dimension between the implant and the reminiscent bone. ${ }^{21}$ After implant installation, a concept of platform switching was employed to allow installation of the provisional prosthesis because previous studies ${ }^{22-24}$ showed greater stability of the soft and hard tissue around the implant, lower stress levels in the peri-implant bone, and preservation of the peri-implant bone height and soft tissue levels.

To prevent horizontal and vertical bone loss and consequently gingival recession and to assure adequate boneto-implant contact, we choose to reconstruct the alveolar buccal bone plate with autogenous bone harvested from the maxillary tuberosity. ${ }^{2,10}$ This approach offers several advantages when compared with bone harvested from other areas in the maxillofacial region, such as easy harvest and adaptation because of the bone malleability, enhanced graft repair, high capacity of revascularization, minimal surgical trauma, discomfort, and pain. ${ }^{14}$ Particulate bone graft was also added to the receptor area to fill the gap between the bone walls and the implant because the previous study ${ }^{25}$ has shown that gap distances $>0.5 \mathrm{~mm}$ result in unpredictable bone formation. Moreover, connective tissue graft harvested from the palate was placed over the bone block graft to increase the thickness and width of the keratinized gingiva, favoring the esthetic results. 

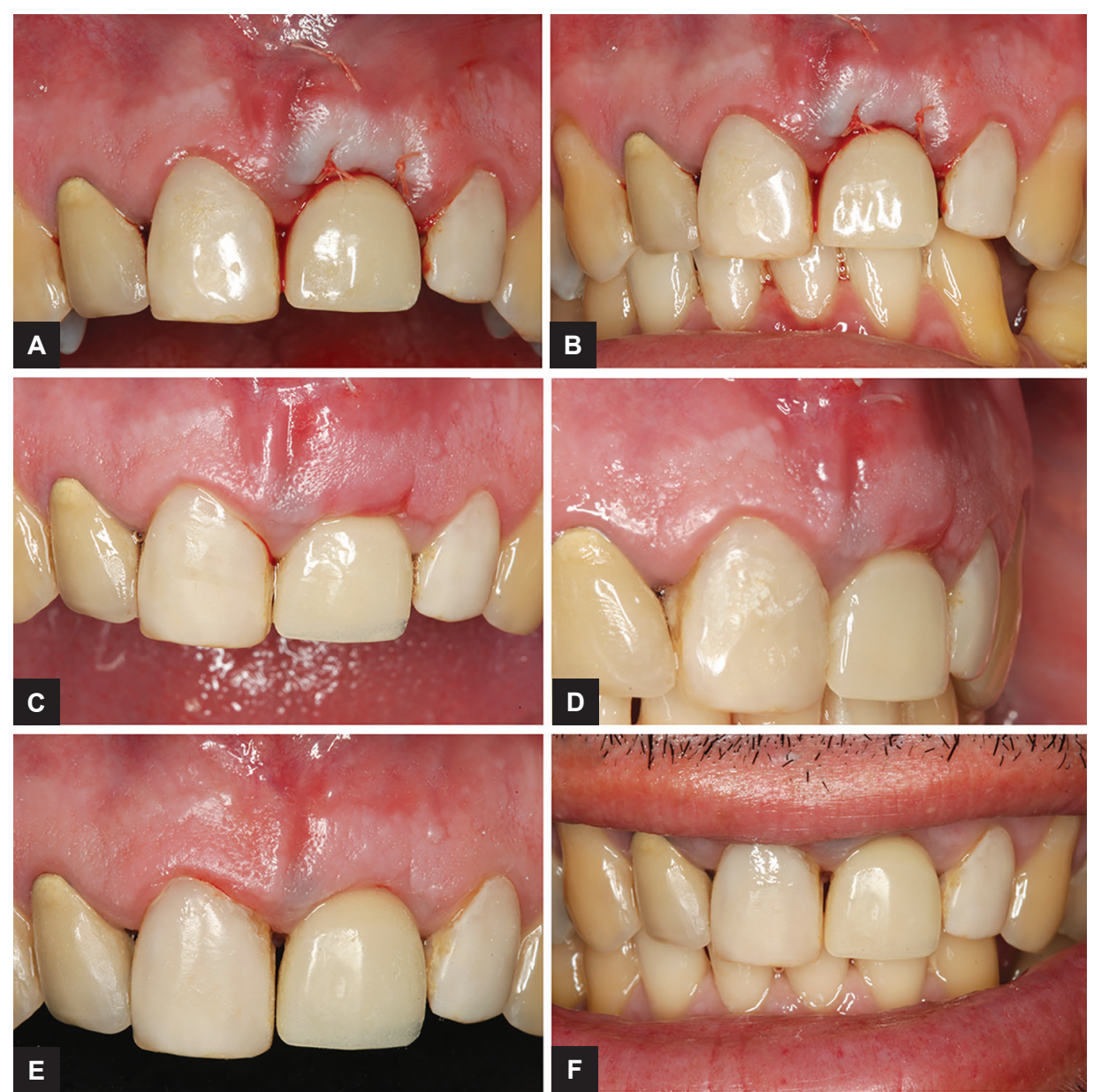

Figs 6A to F: (A and B) Simple interrupted sutures were performed to stabilize the soft and hard tissue graft in position; (C and D) 2 weeks postoperative after suture removal. Increased thickness and width of the gingival tissue could be observed; and ( $E$ and F) 1-year follow-up showing the maintenance of the results achieved with the provisional restoration

\section{CONCLUSION}

In conclusion, when proper diagnosis, precise surgical techniques, and appropriate multidisciplinary approach are employed, IIP followed by immediate dentoalveolar restoration might be considered a safe procedure to restore the peri-implant bone without alveolar bonedimensional changes and gingival recession favoring the achievement of appropriate esthetic outcomes. This treatment planning was able to improve gingival architecture and bone volume with sufficient width and thickness enhancing patient esthetic and satisfaction.

\section{CLINICAL SIGNIFICANCE}

The treatment planning employed was able to improve gingival architecture and bone volume with sufficient width and thickness enhancing patient esthetic and satisfaction in one single-stage procedure.

\section{REFERENCES}

1. Schulte W, Kleineikenscheidt H, Lindner K, Schareyka R. The Tübingen immediate implant in clinical studies. Dtsch Zahnarztl Z 1978 May;33(5):348-359.
2. de Molon RS, de Avila ED, Cirelli JA, Mollo Fde A Jr, de Andrade MF, Filho LAB, et al. A combined approach for the treatment of resorbed fresh sockets allowing immediate implant restoration: a 2-year follow-up. J Oral Implantol 2015 Dec;41(6):712-718.

3. Esposito M, Grusovin MG, Polyzos IP, FeliceP, Worthington HV. Timing of implant placement after tooth extraction: Immediate, immediate-delayed or delayed implants? A Cochrane systematic review. Eur J Oral Implantol 2010 Autumn;3(3):189-205.

4. Hämmerle $\mathrm{CH}$, Araújo MG, Simion M, Osteology Consensus Group. Evidence-based knowledge on the biology and treatment of extraction sockets. Clin Oral Implants Res 2012 Feb;23 (Suppl 5):80-82.

5. Lang NP, Pun L, Lau KY, Li KY, Wong MC. A systematic review on survival and success rates of implants placed immediately into fresh extraction sockets after at least 1 year. Clin Oral Implants Res 2012 Feb;23 (Suppl 5):39-66.

6. Cosyn J, Hooghe N, De Bruyn H. A systematic review on the frequency of advanced recession following single immediate implant treatment. J Clin Periodontol 2012 Jun;39(6): 582-589.

7. Van der Weijden F, Dell'Acqua F, Slot DE. Alveolar bone dimensional changes of post-extraction sockets in humans: a systematic review. J Clin Periodontol 2009 Dec;36(12): 1048-1058. 
8. Vignoletti F, de Sanctis M, Berglundh T, Abrahamsson I, Sanz M. Early healing of implants placed into fresh extraction sockets: An experimental study in the beagle dog. II: ridge alterations. J Clin Periodontol 2009 Aug;36(8):688-697.

9. Vignoletti F, Sanz M. Immediate implants at fresh extraction sockets: From myth to reality. Periodontol 20002014 Oct;66(1):132-152.

10. de Molon RS, de Avila ED, de Barros-Filho LA, Ricci WA, Tetradis S, Cirelli JA, Borelli de Barros LA. Reconstruction of the alveolar buccal bone plate in compromised fresh socket after immediate implant placement followed by immediate provisionalization. J Esthet Restor Dent 2015 May-Jun;27(3):122-135.

11. Schwartz-Arad D, Chaushu G. The ways and wherefores of immediate placement of implants into fresh extraction sites: a literature review. J Periodontol 1997 Oct;68(10):915-923.

12. Buser D, Martin W, Belser UC. Optimizing esthetics for implant restorations in the anterior maxilla: anatomic and surgical considerations. Int J Oral Maxillofac Implants 2004;19 (Suppl):43-61.

13. Hürzeler MB, Weng D. A single-incision technique to harvest subepithelial connective tissue grafts from the palate. Int J Periodontics Restorative Dent 1999 Jun;19(3):279-287.

14. Rosa JC, Rosa AC, Francischone CE, Sotto-Maior BS. Esthetic outcomes and tissue stability of implant placement in compromised sockets following immediate dentoalveolar restoration: results of a prospective case series at 58 months follow-up. Int J Periodontics Restorative Dent 2014 Mar-Apr; 34(2):199-208.

15. Ten Heggeler JM, Slot DE, Van der Weijden GA. Effect of socket preservation therapies following tooth extraction in non-molar regions in humans: a systematic review. Clin Oral Implants Res 2011 Aug;22(8):779-788.

16. Vignoletti F, Discepoli N, Muller A, de Sanctis M, Muñoz F, Sanz M. Bone modelling at fresh extraction sockets: immediate implant placement versus spontaneous healing: an experimental study in the beagle dog. J Clin Periodontol 2012 Jan;39(1):91-97.
17. Horváth A, Mardas N, Mezzomo LA, Needleman IG, Donos N. Alveolar ridge preservation. A systematic review. Clin Oral Investig 2013 Mar;17(2):341-363.

18. Al-Sabbagh M, Kutkut A. Immediate implant placement: surgical techniques for prevention and management of complications. Dent Clin North Am 2015 Jan;59(1):73-95.

19. de Avila ÉD, de Molon RS, de Assis Mollo F Jr, de Barros LA, Capelozza Filho L, de Almeida Cardoso M, Cirelli JA. Multidisciplinary approach for the aesthetic treatment of maxillary lateral incisors agenesis: thinking about implants? Oral Surg Oral Med Oral Pathol Oral Radiol 2012 Nov;114(5):e22-e28.

20. Covani U, Cornelini R, Calvo JL, Tonelli P, Barone A. Bone remodeling around implants placed in fresh extraction sockets. Int J Periodontics Restorative Dent 2010 Dec;30(6): 601-607.

21. deBarros LA, de Almeida Cardoso M, de Avila ED, deMolon RS, Siqueira DF, Mollo-Junior Fde A, Capelloza Filho L. Six-year follow-up of maxillary anterior rehabilitation with forced orthodontic extrusion: achieving esthetic excellence with a multidisciplinary approach. Am J Orthod Dentofacial Orthop 2013 Oct;144(4):607-615.

22. Atieh MA, Ibrahim HM, Atieh AH. Platform switching for marginal bone preservation around dental implants: a systematic review and meta-analysis. J Periodontol 2010 Oct;81(10):1350-1366.

23. Calvo Guirado JL, Saez Yuguero MR, Pardo Zamora G, Muñoz Barrio E. Immediate provisionalization on a new implant design for esthetic restoration and preserving crestal bone. Implant Dent 2007 Jun;16(2):155-164.

24. Canullo L, Rasperini G. Preservation of peri-implant soft and hard tissues using platform switching of implants placed in immediate extraction sockets: a proof-of-concept study with 12- to 36-month follow-up. Int J Oral Maxillofac Implants 2007 Nov-Dec;22(6):995-1000.

25. Knox R, Caudill R, Meffert R. Histologic evaluation of dental endosseous implants placed in surgically created extraction defects. Int J Periodontics Restorative Dent 1991;11(5): 364-375. 